\title{
Prevalence of malaria parasite in takum local government area, taraba state, Nigeria
}

\author{
Abstract \\ Introduction: Blood parasites of the genus Plasmodium are approximately 156 named \\ species, which infects various species of vertebrates. Transmission of malaria is intense \\ and stable in Nigeria because the intensity of attack remains constant throughout the year \\ or from year to year.
}

Objective: This research was conducted in order to determine the prevalence rate of malaria parasite in Takum, Taraba State, Nigeria.

Methods: Studies were carried out in order to determine the prevalence of malaria parasite infection among human beings in Takum, Taraba State. Rapid diagnostic antimalarial kits, structural questionnaires were distributed to ascertain the age, sex, drugs or insecticides used, and state of health of the individuals before cutting them into the study.

Results: Overall, $80(64 \%)$ of the 100 persons investigated were found to have malaria infection. Age groups (0-3years) had the highest frequent rate of $64 \%$ which means parasite density of $90 \%$, and the difference between the age groups was statistically significant ( $\mathrm{p} \leq 0.05$ student; $\mathrm{t}$-test). Children of the illiterates from suburban villages had the highest means parasite density of 850 with $98 \%$ prevalence rate. $20 \%$ of the children were given local herbs and $22 \%$ used orthodox medicine as prophylaxis. Only $18 \%$ used insecticidetreated bed nets while $24 \%$ of the parents spray insecticide to prevent mosquito bites.

Conclusion: The study showed that lack of effective strategies for mosquito control was responsible for high prevalence rate of malaria parasite in Takum. There is the need for more awareness on effective use of anti-malarial drugs and insecticide-treated bed nets in malaria hyper endemic regions of Takum.

Keywords: prevalence, malaria, takum, mosquito, parasite, hyper endemic

\author{
Volume 6 Issue I - 2018
}

\author{
Ukwubile Cletus A,' Tzozon Krustu,' \\ Cynthia T Samagoro, ${ }^{2}$ Odogu Jude ${ }^{3}$ \\ 'Department of Science Laboratory Technology, Federal \\ Polytechnic Bali, Nigeria \\ ${ }^{2}$ Department of Pharmacognosy and drug development, Gombe \\ State University, Nigeria \\ ${ }^{3}$ Department of Medical Microbiology, Ahmadu Bello University \\ Teaching Hospital Shika, Nigeria
}

Correspondence: Ukwubile Cletus A, Department of Science Laboratory Technology, Federal Polytechnic Bali, Taraba State, Nigeria,Email doccletus@yahoo.com

Received: December 09, 2017| Published: February 20, 2018

\section{Introduction}

Blood parasites of the genus plasmodium are approximately 156 named species, which infects various species of vertebrates. Four species were considered true parasite of humans as they utilized human almost exclusively as natural intermediate host. ${ }^{1}$ The species P. falciparum, $P$. vivax $P$. ovale and P. malariae. However, there are periodic reports of simian malaria parasite being food in human's most reports implicating $P$. knowless has not been determined. Over $80 \%$ of malaria infections are caused by $P$. falciparum while up to $15 \%$ are caused by P. malariae and less than $5 \%$ are caused by P. ovale infections. Mixed infections with $P$. falciparum are common. ${ }^{2-4}$ Mbanugo \& Ejim, ${ }^{5}$ in a study conducted in three hospitals and a Nursery School in Awka on prevalence of Plasmodium infections in children, discovered that out of 400 children, 233(58\%) were positive and only Plasmodium falciparum were found. Among the positive cases $85.5 \%$ were observed in age group 2-3 while $33 \%$ was in 0 -1years indicating that the prevalence of Plasmodium infections among under 5 children is significantly affected by age. Sex in their findings did not affect prevalence rate. The major vectors of human malaria are Anopheles gambiae, Anopheles funestus, Anopheles arabiensis and Anopheles melas. A arabiensis is most dominant in the savannah areas and cities. A gambiae are found in highly dense forest areas, A. funestus has an uneven distribution while $A$. melas is a salt water species. ${ }^{6}$ Anopheles mosquitoes can adapt to urban breeding sites over time e.g., in India, Anopheles stephensis has developed into urban species and is found in much higher numbers in many cities in India than in the surrounding country side. ${ }^{6}$ There is evidence that Anopheles mosquitoes are likewise becoming better adapted to the breeding site of Accra. ${ }^{7}$ Transmission of malaria is intense and stable in Nigeria because the intensity of attack remains constant throughout the year or from year to year. The degree of endemicity of malaria measured is based on the spleen rate in children aged 2-9years as published, in their order of severity. Hypo endemic malaria occurs when spleen rate in children is less than $10 \%$. Mesoendemic malaria occurs when spleen rate in children is $11-50 \%$. Hyperendemic malaria occurs when spleen rate is $75 \%$ in children and $>25 \%$ in adults. Holoendemic malaria occurs when spleen rate is $>75 \%$ in children but very low in adults. $P$. falciparum is the predominant species in the world $P$. vivax and $P$. ovale are traditionally thought to occupy complementary riches, with P. vivax in other areas, but their geographical ranges do overlap.

There are two species which are not always distinguishable on the basis of morphologic characteristic alone, and the use of molecular tools will help clarify their diagnosis and exert distribution. $P$. malariae has wide global distribution, being found in South America, Asia and Africa, but it is less frequent than P. falciparum. P. knowless is present in about 102 countries and infect up to 500million people and causes 2.5 million on death, annually, primarily in the tropics ${ }^{8}$ malaria is one of the three infectious diseases that contributed most significantly to the burden of diseases estimated yearly.

The most malaria infections worldwide, the most serious and often fatal form of malaria is caused by $P$. falciparum. In many parts 
of Nigeria, infected people can stay without showing any sign or symptoms for blood feeding serving as reservoirs of infections for blood feeding mosquitoes. Malaria parasites enter the humans host through the bite of infected female mosquitoes. The life cycle of malaria parasite take place in two separate cycles, one in the human or (vertebrates) host and the other, in the mosquitoes. This research was conducted in order to determine the prevalence rate of malaria parasite in Takum, Taraba State.

\section{Materials and methods}

In this study, the following materials were used: tourniquet, dry sterile syringe and needle $(5 \mathrm{~mL}), 70 \%$ alcohol (methylated spirit), dry bottle, cotton wool, hand gloves, blood sample; all these materials were sterilized before used to prevent any form of contaminations.

Tourniquet was tied to the fore arm of human hosts that were randomly selected from the study areas, to create pressure and therefore, cotton wool soaked in $70 \%$ alcohol was used to clean the surface of the skin to expose the veins. If the veins are not prominent enough the patient was ask to straight the arm and squeeze a universal bottle so that there will be more pressure in the vein, $5 \mathrm{~mL}$ syringe needle was used to select a thin vein by inserting it into anti-cubical vein for blood sample collection while anticoagulant was added to make the blood sample settle.

Finally, the sample was decanted, then the serum was dropped in the portion of sample on rapid diagnostic test strip and allowed to stand for 2 to 5 minutes before the results were taken. ${ }^{9}$

\section{Statistical analysis}

Raw data obtained were subjected to statistical analysis using mean \pm SEM as well as one way ANOVA (Analysis of Variance) at $\mathrm{p} \leq 0.05$.

\section{Results}

Results are $\%$ of real data, $* \mathrm{P} \leq 0.05$ (statistical significance; one way ANOVA), $\infty$ (lowest percentage infection).

From Table 1 above, persons living in Kakum area have 100\% prevalence rate due the presence of water and dirt in most places sampled. However, high level of mosquito control awareness in Dama area contributed to low level of prevalence seen in Table 1.

Table I Prevalence of malaria parasite in takum, takum LGA, Taraba State, Nigeria

\begin{tabular}{lllll}
\hline Area & $\begin{array}{l}\text { № of } \\
\text { people } \\
\text { examined }\end{array}$ & $\begin{array}{l}\text { No \% } \\
\text { infected }\end{array}$ & $\begin{array}{l}\text { No } \\
\text { uninfected }\end{array}$ & \% Prevalence \\
\hline Kashimbila & 17 & 11 & 6 & 64.7 \\
Fadama & 14 & 10 & 4 & $71.4^{*}$ \\
Kakum & 12 & 11 & 1 & $91.7^{*}$ \\
Dama & 15 & 4 & 11 & $26.7^{\infty}$ \\
Manya & 4 & 4 & 0 & $100.0^{*}$ \\
Chanchanji & 12 & 6 & 6 & 50 \\
Pygi & 2 & 1 & 1 & 50 \\
Tati & 11 & 9 & 2 & $81.8^{*}$ \\
Muji & 13 & 6 & 7 & 46.2 \\
Total & 100 & 62 & 38 & 582.5 \\
\hline
\end{tabular}

In Table 2, the children and the elderly were mostly affected. This is because of lack of high immune system to withstand the level of parasitaemia shown by Plasmodium in its host. Also, high prevalence rate of infections were recorded in females especially pregnant ones than the males $71.43 \%$ (Table 3 ) in the all the areas sampled. It is possible that the males developed more immunity to plasmodium infection than the females in these areas or the genotypes of the males might have contributed; for it has been reported that certain genotypes show resistance to malaria infection than the others. ${ }^{9}$

Table 2 Distribution of malaria parasite in various age groups in takum

\begin{tabular}{lllll}
\hline Age & $\begin{array}{l}\text { № people } \\
\text { examined }\end{array}$ & № infected & № uninfected & \% Prevalence \\
\hline $0-10$ & 30 & 20 & 10 & $66.67^{*}$ \\
$11-20$ & 14 & 9 & 6 & 60 \\
$21-30$ & 11 & 4 & 7 & 36.36 \\
$31-40$ & 7 & 2 & 5 & $28.57^{\circ}$ \\
$41-50$ & 8 & 5 & 3 & 62.5 \\
$51-60$ & 9 & 4 & 5 & 44.44 \\
$61-70$ & 11 & 7 & 4 & 63.64 \\
$71-80$ & 2 & 2 & 0 & $100.00^{*}$ \\
$81-90$ & 3 & 2 & 1 & $66.67^{*}$ \\
$\Sigma$ & 100 & 55 & 41 & 337.25 \\
\hline
\end{tabular}

Results are \% of real data, $* \mathrm{P} \leq 0.05$ (statistical significance; one way ANOVA), $\Sigma$ (summation), ${ }^{\infty}$ (lowest percentage infection).

Table 3 Distribution of malaria parasite among difference sexes in takum

\begin{tabular}{lllll}
\hline Sex & $\begin{array}{l}\text { № of people } \\
\text { examined }\end{array}$ & № infected & № uninfected & $\begin{array}{l}\% \\
\text { Prevalence }\end{array}$ \\
\hline Male & 51 & 25 & 26 & $49.02^{\circ}$ \\
Female & 49 & 35 & 14 & $71.43^{*}$ \\
$\Sigma$ & 100 & 60 & 40 & 120.45 \\
\hline
\end{tabular}

Results are \% of real data, ${ }^{P} \leq 0.05$ (statistical significance; student's t-test), $\Sigma$ (summation), ${ }^{\infty}$ (lowest percentage infection).

\section{Discussion}

Malaria has been known to be the cause of a worldwide infection especially in children and pregnant women. From the results obtained in this present study, malaria today is usually restricted to tropical and subtropical areas. Areas like Manya, Kakum and Fadama, have the highest $\%$ prevalence than Muji, because there is availability of water where Anopheles mosquito would easily lay their eggs. Whereas people living in Dama and Muji areas have low\% prevalence of 26.67 and 46.15 , because majority of people living there are elites, who have immense knowledge of mosquito control, as well as the knowledge of the life cycle of mosquito, and thus controlling the population by spraying all stagnant water bodies with chemicals such as oil, kerosene and premium motor spirit (fuel). All these prevent the larvae from breathing and the sink to the bottom of the water and subsequently die. ${ }^{10}$

Proper environmental hygiene like bush clearing including draining of water from gutters were some of the measures taken by settlers in Muji area to deny mosquitoes their breeding sites. Majority of the people infected with malaria are people of age group 0-10, 71$80,81-90$ and pregnant women, because they have weak immune 
system as a result of excessive destruction of the white blood cell type IgA and IgM by monoclonal antigens at these ages. ${ }^{11}$

Finally, females had a significant higher\% prevalence rate than the males from the data obtained. The study also showed that malaria is a major public health problem in Takum, among the pregnant women, children and the aged due to weak immune systems to fight the sporozoites and merozoites at various stages of development, as well as improper environmental hygiene like bush clearing, and water drainages which serves as breeding site for mosquito vectors. ${ }^{12-20}$

The overall prevalence rate of this protozoan parasite in Takum was above $80 \%$, which points to the fact that people in Takum and its environs did not see malaria infection as a more deadly disease than even HIV /AIDS or hepatitis B. This was due totally negligence in the call for a fight against malaria from all nooks and crannies of the globe.

\section{Conclusion}

Our study revealed that, high prevalence rate of malaria among the people of Takum is mostly in pregnant women and children of age $0-10 y e a r s$ as well as the elderly, because their weak immune system to fight the parasite than the average ages, which are ever conscious of the menace resulting from indiscriminate mosquito bites. The study therefore, showed that malaria is still a major problem in Takum because of the presence of factors that encourage the breeding of mosquitoes in most of the sampled areas. Also the lack of effective malaria control strategies poses a problem around Manya, Kakum and Fadama areas, with highest $\%$ infection of malaria parasite.

\section{Acknowledgements}

The authors are grateful to the people of Takum town for all assistance rendered in this work

\section{Project fund number}

This research was funded by all authors in this article and not funded by any agency.

\section{Conflict of interest}

The author declares no conflict of interest.

\section{References}

1. Afrance YA, KlinkensaryE, Drechsel P, et al. Irrigated Urban agriculture influence the Transmission of malaria in the city of Kumasi Ghana. Act Tropica. 2010;89(2):125-134.

2. Bashir M. Beware of Malaria Cases. Nigeria: Deice Truss; 2009. 28:37.

3. Carmel B, Kerumogue D, Copui FB, et al. Annals of Plasmodium prevalence Parasite burden in blood donors of Brazzaville. Cang. Society for Belgium Medicine tropical. 2012;73:179-187.
4. Ejeszie GG. The Nigeria Environmental and Parasitic Infections. Folia Parasite. 2010;30:80-95.

5. Mbanugo KI, Ejim CI. Seasonal Variation in malaria episodes among residents in Udi, a semi-urban community in southeast Nigeria. The Nigeria Journal of Parasitology. 2013;19:39-43.

6. Federal Ministry of Health. National Strategic Plan for Roll Back Malaria in Nigeria. Abuja Malaria Conference Paper, 2009. 23(12):34-41.

7. Helen IG, Robert WW. The Epidemiology and burden of Plasmodium falciparum-Related Anemia among pregnant women in subSaharan Africa. American journal for tropical medicine and hygiene. 2012;64(1\&2):36-44.

8. Hoffman NS, Hughes JO, Peterson LM. Prevalence of malaria parasite in Children age $0-5$ years on dried blood spots. American Journal of tropical Medicine. 2013;5(2):72-82.

9. Ofili IG. Investigating antimalarial potentials of an ethno medicinal formulation-Herbal 25®. Journal of ethno pharmacology. 2012;8(3):4552

10. Ogunledun A, Kofire IA, Fakoya GB, et al. Prevalence and significance of symptomatic and asymptomatic malaria Parasitaemia in Shagamu, Nigeria. The Nigeria Journal of Parasitology. 2011;9(11):149-156.

11. Okonko, Soleye FA, Amusan TA, et al. Prevalence of malaria plasmodium in Abeokuta, Nigeria. Malaysian Journal of Microbiology. 2009;5(2):113-113.

12. Ukwubile CA. Phytochemical Screening and Anti-biotic Potentials of Pycnathus angolensis (Welw.) Warb (Myristicaceae) bark juice. Journal of Medical and Applied Biosciences. 2012;2:10-15.

13. WHO. Malaria Fact Sheet No 94. Switzerland: World Health Organization; 2015.

14. CDC (Centre for Disease Control). Atlanta co 800-CDC-info. USA: US Department and Health; 2012.

15. NMFS (Nigeria Malaria Fact Sheet). United States Embassy in Nigeria. 2011.

16. Cheesbrough M. "District Laboratory Practice in Tropical Countries". 2nd ed. update Part 1. UK: Cambridge University Press; 2006. p. 239 242 .

17. WHO. Malaria diagnosis, new perspectives. Switzerland: World Health Organization; 2000.

18. Okafor HU, Oguonu T. Epidemiology of malaria in infancy at Enugu, Nigeria. See comment in PubMed Commons below Niger J Clin Pract. 2006;9(1):14-17.

19. Ukpai OM, Ajoku EI. The prevalence of Malaria in Okigwe and Owerri areas of Imo State. Niger J Clin Pract. 2001;22(1):43-48.

20. Olasehinde GI, Ajayi AA, Taiwo SO, et al. Prevalence and Management of Faciparium Malaria among infants and children in Ota, Ogun State, South western Nigeria. African Journal of Clinical and Experimental Microbiology. 2010;11:159-163. 